CASE REPORTS

\title{
Primary unruptured ovarian pregnancy with intrauterine device
}

\author{
RASSUl S. SABER \\ M.D. \\ Department of Pathology, Chippewa County War Memorial Hospital, \\ 500 Osborn Boulevard, Sault Ste Marie, Michigan 49783, U.S.A.
}

\begin{abstract}
Summary
A case of intrafollicular and unruptured ovarian pregnancy associated with intrauterine device which meets the rigid criteria of Spiegelberg (1878) is presented. Clinically, unruptured cases can be confused with ovarian cysts. Intrauterine devices are highly effective for protection against uterine gestation and to a lesser degree against tubal gestation, but they have no effect in preventing ovarian gestation.
\end{abstract}

\section{Case report}

A 28-year-old white female was admitted to the hospital with the chief complaint of lower abdominal pain for 4 days' duration and of having fainted at home three times, She was gravida 2, para 1, abortus 1 , and had had an intrauterine device (regular size, Margulies Spiral or 'Gynekoil') for 5 years. Her last menstrual period had begun 3 weeks before admission and had continued with a light intermittent flow. Previous periods had been normal. The patient also complained of some vague chest and shoulder pain with nausea. Her temperature and blood pressure were within normal limits. Her pulse, however, was $104 / \mathrm{min}$. Abdominal examination showed slight generalized tenderness with no rebound and no mass. Pelvic examination revealed slight fullness of the left adnexal area with a normal uterus and correctly placed intrauterine device. Culdocentesis was performed twice at 24-hr intervals and was negative both times. Routine urinalysis was normal. Pregnancy test (OGS method*) on urine, repeated three times at 48-hr intervals, proved positive each time. Results of routine admission tests (SMA 12) (glucose; BUN; uric acid; calcium; alkaline phosphatase; SGOT; LDH; total protein; albumin; total bilirubin; cholesterol; phosphorus) including amylase were within normal limits. Haemoglobin

\footnotetext{
* Ortho Gravindex Qualitative Slide Test based on agglutination of latex coated with HCG by rabbit serum antiHCG and neutralization of anti-HCG with an HCG present in positive urine.
}

was $13.5 \mathrm{~g} / 100 \mathrm{ml}$; haematocrit, $41 \%$; WBC $9,400 / \mathrm{mm}^{3}$ with normal differentiation. Routinés chest X-ray was negative, and plain abdomina ${ }_{V}$ $X$-ray was normal showing IUD to be in place.

She was pain-free on the second day of admission $N$ and remained so during the hospital course. Repeat haemoglobin and haematocrit on the following days showed no significant changes and remained stable 3 Pelvic examination on the day before discharge revealed normal findings with no masses. Because of improvement she insisted upon going home, añ deํำ was subsequently discharged, clinically improved, after 8 days in hospital. The final diagnosis waspar suspected early intrauterine pregnancy with IUTs failure, based on the positive pregnancy test and के questionable ovarian cyst which had subsided. She was advised to return whenever the previous symp $\Omega$ toms reappeared and also for a weekly pelvic examination and pregnancy test.

Twenty-four days later she was readmitted with a sudden onset of severe cramping pain in the lefo lower quadrant of the abdomen which became worse when moving. There was no vaginal bleeding andB. she did not appear in a state of collapse. Bloodb pressure was $130 / 75 \mathrm{mmHg}$ with regular pulse af. $84 / \mathrm{min}$ and temperature of $98^{\circ} \mathrm{F}$. Pelvic examination revealed a tender, $8-\mathrm{cm}$ cystic mass in the lefe adnexal area. The uterus appeared to be slightlyo enlarged but freely movable. Routine SMA 12 tests were normal. Haemoglobin was $12.9 \mathrm{~g} / 100 \mathrm{ml}$ and? haematocrit was $40 \%$. WBC was $8,200 / \mathrm{mm}^{3}$ with normal differentiation. Routine urinalysis was normal. The urine pregnancy test (OGS method) was positive. X-rays of chest and flat plate of abdomerts were negative; IVP showed a pelvic soft-tissue masso The clinical appearance was of ectopic gestation of ruptured ovarian cyst.

Laparotomy revealed the left ovary to be large and cystic, freely attached to the utero-ovariano ligament and separated from the left tube by meso salpinx. No site of haemorrhage was seen. The cystiœ 


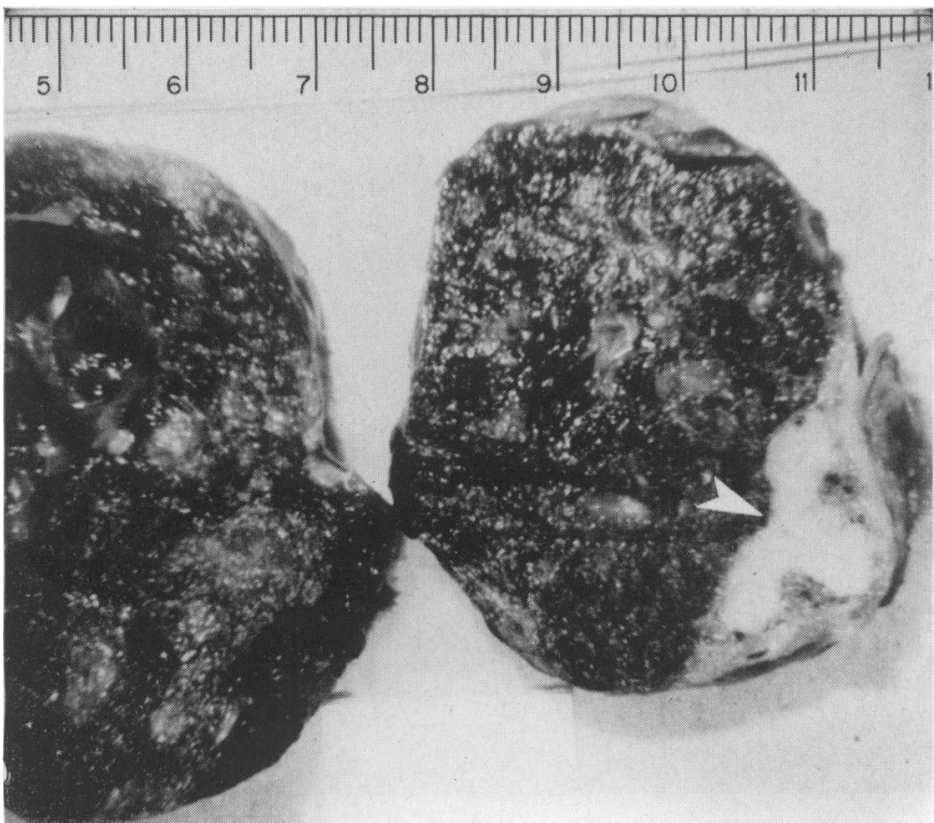

Fig. 1. Left ovary showing partial replacement by gestational sac, with corpus luteum of pregnancy seen on the right (arrow).

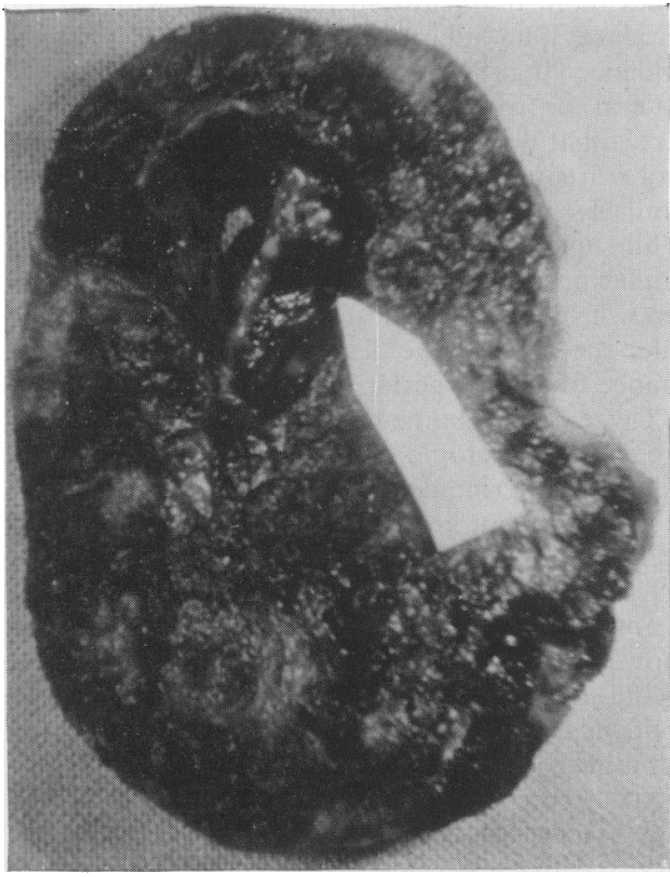

FIG. 2. Embryonic sac with degenerated embryo and gestational sac (arrow). ovarian mass was freed from its pelvic adhesions and a left oophorectomy was carried out. The uterus, right adnexa and left tube were unremarkable.

The ovarian mass measured $7 \times 6 \times 4.5 \mathrm{~cm}$; most of the external surface was smooth with a few areas of fibrous adhesions; no site of rupture was seen. The sections revealed a haemorrhagic cystic mass representing the gestational sac, in one part of which a large corpus luteum of pregnancy was seen (Fig. 1). In the proximate centre of the gestational sac there was one embryonic sac, $3 \mathrm{~cm}$ in the largest dimension, with a thin, translucent membrane and a $1-\mathrm{mm}$ degenerated embryo (Fig. 2). Microscopically, the gestational sac was implanted in the ovarian tissue, surrounded by corpus luteum of pregnancy and oedematous cortex of ovary. The wall of the gestational sac was haemorrhagic, consisting of placental membranes and immature chorionic villi with trophoblastic giant cells, which infiltrated an active corpus luteum, indicating an intrafollicular-type ovarian pregnancy (Fig. 3). There was no evidence of endometriosis of the ovary.

The patient was discharged after 8 days. Three pregnancy tests carried out at weekly intervals became negative after 2 weeks. 


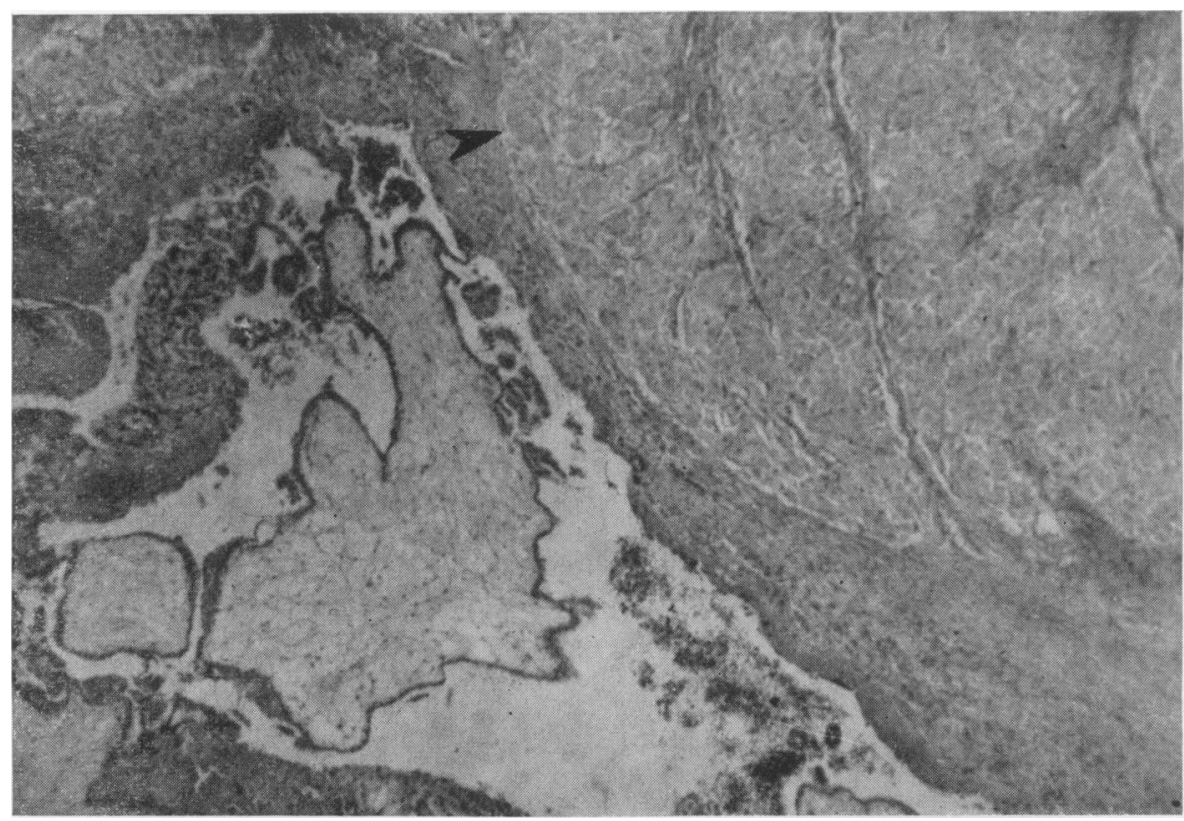

FIG. 3. Microscopic section of ovary showing chorionic villi with trophoblastic giant cells infiltrating the corpus luteum of pregnancy (arrow) $\mathrm{H} \& \mathrm{E}, \times 70$.

\section{Discussion}

Ovarian pregnancy is a rare form of ectopic pregnancy and should be diagnosed according to the criteria established by Spiegelberg (1878): (1) the tube of the affected side must be normal; (2) the gestational sac must occupy the normal position in the ovary; (3) the sac must be connected to the uterus by the ovarian ligament; (4) unquestionable ovarian tissue must be demonstrable in the wall of the sac. Reported incidence of this is estimated by Hertig (see Gérin-LaJoie, 1951) as $0.7-1.7 \%$ of all ectopic gestations and one in $25,000-40,000$ pregnancies. Isbell and Bacon (1947) have claimed that the known incidence of ovarian pregnancy would be increased if every haemorrhagic ovarian lesion such as chocolate cyst, haemorrhagic corpus luteum, etc., were subjected to microscopic examination. Also, Campbell et al. (1974) recommended that a check for occult ovarian pregnancy be made in cases of acute hemoperitoneum, especially if an IUD were present. Various aetiological mechanisms have been proposed by Boronow et al. (1965): obstructive ovulation, e.g. pelvic inflammatory disease; ineffective tubal function; favourable surface phenomena, e.g. endometriosis; parthenogenesis; chance. The clinical manifestations are commonly confused with tubal pregnancy and ruptured ovarian cyst. The unruptured cases are diagnosed extremely rarely and are mistaken for ovarian cyst.

It has been claimed by Tietze (1968) and studies by Lehfeldt, Tietze and Gorstein (1970) ho by Lehfeldt, Tietze, and Gorstein (1970) haqe shown that ectopic gestation occurs almost tent times more frequently in pregnancies with an IUTO in place than all other pregnancies. There is no evidence that IUDs cause ectopic gestation in? general or ovarian pregnancy in particular. The fact is that women using IUDs become pregnant far more frequently than the fertile control groupô similarly exposed to conception (Craig, 1975). $\frac{3}{\sigma}$ While non-IUD users are pregnant only once a year, similar groups with IUDs are fertilized at least four times in the same year (Lehfeldt et al., 1970). As a을 rule, the oftener the fertilization, the greater the chance of ectopic gestation.

Tietze (1968) claimed that the incidence of ovariani pregnancy in ectopic pregnancies was $1: 7$ in those using intrauterine devices as compared with $1: 150$ in those without intrauterine devices. This incidence accorded with reports by Pugh, Vogt and Gibsono (1973). The exact mechanism of action of an IUDis not well known. A study by Lehfeldt et al. (1970) N showed that the IUD reduces uterine implantation by about $99.5 \%$, tubal implantation by $95 \%$ and the incidence of ovarian pregnancy not at all. Their hypothesis is that at the site of the IUD, the endometrium produces some chemical agent which is: highly effective in preventing implantation in the uterus, with a lesser degree of effectiveness in the tube and no effect in the ovary. In relation to this hypo thesis, Morris and van Wagenen (1973) claim there is 
evidence that IUDs or a high dose of oestrogens taken post-coitally decrease endometrial carbonic anhydrase, and subsequently prevent uterine implantation.

\section{Conclusion}

Ovarian ectopic gestation is relatively rare and usually difficult to recognize before laparotomy. It is almost always ruptured at the time of exploration. The increasing reported incidence of ovarian pregnancy has a close relationship to the increased usage of IUDs and also to the greater awareness of physicians to this type of ectopic pregnancy. Specifically, more haemorrhagic ovaries are being subjected to wedge resection or total removal and careful sectioning for detection of ovarian pregnancy.

\section{Acknowledgments}

I would like to thank Dr Henry Puro and Dr Hushang Payan for their advice, and Miss Barbara James for her technical assistance.

\section{References}

Boronow, R.C., McElin, T.W., West, R.H. \& BuckingHAM, J.C. (1965) Ovarian pregnancy (report of four cases and a thirteen-year survey of the English literature). American Journal of Obstetrics and Gynecology, 91, 1095.

Campbell, J.S., Hacquebard, D.M., Mitton, D.M., Hurteau, G.D., Bobra, S.T. \& Sirois, J. (1974) Acute hemoperitoneum, IUD, and occult ovarian pregnancy. Obstetrics and Gynecology, 43, 438.

Craig, J.M. (1975) The pathology of birth control. Archives of Pathology, 99, 233.

Gérin-LAJoIE, L. (1951) Ovarian pregnancy. American Journal of Obstetrics and Gynecology, 62, 920.

IsBelL, N.P. \& BACON, W.B. (1947) Primary ovarian pregnancy. American Journal of Obstetrics and Gynecology, 54, 329.

Lehfeldt, H., Teitze, C. \& Gorstein, F. (1970) Ovarian pregnancy and the intrauterine device. American Journal of Obstetrics and Gynecology, 108, 1005.

MORRIS, J.M. \& VAN WAGENEN, G. (1973) Interception: the use of postovulatory estrogens to prevent implantation. American Journal of Obstetrics and Gynecology, 115, 101.

Pugh, W.E., Vogt, R.F. \& Gibson, R.A. (1973) Primary ovarian pregnancy and the intrauterine device. $O b$ stetrics and Gynecology, 42, 218.

SPEIGELberg, O. (1878) Zur Casuistik der Ovarialschwangerschaft. Archiv für Gynäkologie, 13, 73.

TIETZE, C. (1968) Correspondence. American Journal of Obstetrics and Gynecology, 101, 275.

Postgraduate Medical Journal (March 1977) 53, 155-156.

\title{
Septic abortion due to invasive Salmonella agona
}

\author{
A. P. BALl \\ B.Sc., M.B., Ch.B., M.R.C.P. (U.K.) \\ R. FOTHERGILL \\ M.B., Ch.B., M.R.C.S., L.R.C.P.
}

East Birmingham Hospital (Department of Communicable and Tropical Diseases), Birmingham B9 5ST

SEPTIC abortion is rarely associated with organisms other than clostridia, staphylococci, streptococci and anaerobes which are introduced into the uterus. Septic abortion occurring as a complication of an invading blood-borne pathogen is extremely uncommon. The present patient is interesting in that Salmonella agona, which until 1970 was an unusual serotype (Leading Article, 1971), was the cause of a septic abortion due to intrauterine infection consequent on a septicaemic illness.

\section{Case report}

The patient, a previously healthy 28-year-old primigravid housewife, who was 14 weeks pregnant,

Correspondence: Dr A. P. Ball, Department of Communicable and Tropical Diseases, Bordesley Green East, East Birmingham Hospital, Birmingham B9 5ST. was admitted to hospital with a 2-day history of malaise, fever and lower abdominal pain followed $24 \mathrm{hr}$ later by rigors and vaginal bleeding containing products of conception. On admission, she was flushed and sweating with a pyrexia of $39 \cdot 4^{\circ} \mathrm{C}$, a tachycardia of 100 and a blood pressure of $120 / 70$ $\mathrm{mmHg}$. The abdomen was distended and there was guarding and tenderness in both iliac fossae. Vaginal examination revealed fresh blood appearing from a soft, one-finger dilated cervix and bimanual examination elicited marked tenderness of the uterus and the lateral fornices. A diagnosis of incomplete septic abortion was made and the patient received ampicillin $500 \mathrm{mg}$ i.m. followed by amoxycillin 500 $\mathrm{mg} / 8 \mathrm{hr}$ thereafter. The vaginal bleeding continued and another vaginal examination revealed a furtherdilated cervix with placental remnants protruding. 